\title{
Methicillin-sensitive Staph. aureus (MSSA) and methicillin-resistant Staph. aureus (MRSA) bacteraemia decline simulaneously
}

\author{
R Coello ${ }^{1}$, ET Brannigann ${ }^{2 *}$, J Wilson ${ }^{1}$, M Richards' ${ }^{1}$, S Hassall ${ }^{1}$, A Jepson ${ }^{3}$, A Holmes $^{2}$ \\ From International Conference on Prevention \& Infection Control (ICPIC 2011) \\ Geneva, Switzerland. 29 June - 2 July 2011
}

\section{Introduction / objectives}

The recent decline in MRSA infection is well recognised but the contribution of hospital-acquired (HA) versus community-acquired (CA) is not always clear, nor if MRSA has substituted for MSSA or is an additional burden. We examined our experience with S.aureus bacteraemia (SAB).

\section{Methods}

From April 2008 to March 2010, at Imperial College Healthcare NHS Trust (ICHNT), electronic microbiological records of patients with SAB were linked with patient administration data to determine if the $S$. aureus was meticillin-sensitive or resistant, and if infection was CA or HA. SAB within 2 days of admission was defined as CA, 2 days or more after admission as HA and a new episode if more than 2 weeks between 2 positive $\mathrm{SAB}$.

\section{Results}

Of 345 SAB detected, $60 \%$ were CA and $40 \%$ HA; 250 (72\%) were MSSA and 95 (28\%) MRSA. Of MRSA bacteraemias, $49 \%$ were $\mathrm{HA}$, but $37 \%$ of MSSA bacteraemias were HA. The rate of SAB per 100,000 bed-days had a downward trend due a decrease in both MRSA and MSSA bacteraemia. Since April 2009, the number of HA MRSA and MSSA decreased simultaneously. During the period April 2008 to March 2009, the rate of HA SAB was 19.6. In the period April 2009 to March 2010 this declined by to 11.7. Between these two periods the rates of MRSA and MSSA bacteraemia rates decreased by 1.7 (from 19.6 to 11.7), 2.1 (from 7.2 to 3.4 ) and 1.5 times (from 12.4-8.3).

${ }^{2}$ Infectious Diseases; Infection Prevention Control, Imperial College Healthcare NHS Trust, London, UK

Full list of author information is available at the end of the article

\section{Conclusion}

$S$. aureus as a cause of bacteraemia at ICHNT is decreasing, particularly HA cases. MRSA and MSSA bacteraemia are decreasing simultaneously, suggesting either that MRSA substituted MSSA rather than reflecting additional cases or that MRSA control measures may also have had an effect on MSSA.

\section{Disclosure of interest}

None declared.

\section{Author details}

${ }^{1}$ Infection Prevention and Control, Imperial College Healthcare NHS Trust, London, UK. ${ }^{2}$ Infectious Diseases; Infection Prevention Control, Imperial College Healthcare NHS Trust, London, UK. ${ }^{3}$ Microbiology, Imperial College Healthcare NHS Trust, London, UK.

Published: 29 June 2011

doi:10.1186/1753-6561-5-S6-P232

Cite this article as: Coello et al:: Methicillin-sensitive Staph. aureus (MSSA) and methicillin-resistant Staph. aureus (MRSA) bacteraemia decline simulaneously. BMC Proceedings 2011 5(Suppl 6):P232.

Submit your next manuscript to BioMed Central and take full advantage of:

- Convenient online submission

- Thorough peer review

- No space constraints or color figure charges

- Immediate publication on acceptance

- Inclusion in PubMed, CAS, Scopus and Google Scholar

- Research which is freely available for redistribution 